\title{
Article
}

\section{Can better management of periodontal disease delay the onset and progression of Alzheimer's disease?}

Harding, Alice, Robinson, Sarita Jane, Crean, Stjohn and Singhrao, Simarjit Kaur

Available at http://clok.uclan.ac.uk/17325/

Harding, Alice, Robinson, Sarita Jane ORCID: 0000-0002-4237-5412, Crean, Stjohn ORCID: 0000-0001-9336-8549 and Singhrao, Simarjit Kaur ORCID: 0000-0001-9573-5963 (2017) Can better management of periodontal disease delay the onset and progression of Alzheimer's disease? Journal of Alzheimer's Disease, 58 (2). pp. 337-348. ISSN 1387-2877

It is advisable to refer to the publisher's version if you intend to cite from the work.

For more information about UCLan's research in this area go to

http://www.uclan.ac.uk/researchgroups/ and search for <name of research Group>.

For information about Research generally at UCLan please go to http://www.uclan.ac.uk/research/

All outputs in CLoK are protected by Intellectual Property Rights law, including Copyright law. Copyright, IPR and Moral Rights for the works on this site are retained by the individual authors and/or other copyright owners. Terms and conditions for use of this material are defined in the policies page.

\section{CLoK}

Central Lancashire online Knowledge www.clok.uclan.ac.uk

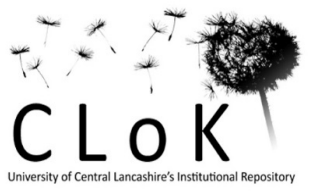


Can better management of periodontal disease delay the onset and progression of Alzheimer's disease?

Authors: Alice Harding, Sarita Robinson ${ }^{1}$, StJohn Crean, Sim K. Singhrao*

Dementia \& Neurodegenerative Diseases Research Group,

Faculty of Clinical and Biomedical Sciences, School of Dentistry,

${ }^{1}$ Faculty of Science and Technology, School of Psychology,

University of Central Lancashire, Preston, PR1 2HE, UK.

Running Title: Restraining infections

${ }^{*}$ Correspondence to:

Sim K. Singhrao,

University of Central Lancashire, Preston, PR1 2HE. UK

Email: sksinghrao@uclan.ac.uk 


\begin{abstract}
A risk factor relationship exists between periodontal disease and Alzheimer's disease (AD) via tooth loss, and improved memory following dental intervention. This links the microbial contribution from indigenous oral periodontal pathogens to the manifestation of chronic conditions, such as AD. Here, we use Porphyromonas gingivalis infection to illustrate its effect on mental health. $P$. gingivalis infection, in its primary sub-gingival niche, can cause polymicrobial synergy and dysbiosis. Dysbiosis describes the residency of select commensals from the oral cavity following co-aggregation around the dominant keystone pathogen, such as $P$. gingivalis, to gain greater virulence. The initial process involves $P$. gingivalis disturbing neutrophil mediated innate immune responses in the healthy gingivae and then downregulating adaptive immune cell differentiation and development to invade, and subsequently, establish new dysbiotic bacterial communities. Immune responses affect the host in general and functionally via dietary adjustments caused by tooth loss. Studies from animals orally infected with P. gingivalis confirm this bacterium can transmigrate to distant organ sites (the brain) and contribute towards peripheral and intracerebral inflammation, and compromise vascular and microvascular integrity. In another study, $P$. gingivalis infection caused sleep pattern disturbances by altering glial cell light/dark molecular clock activity, and this, in turn, can affect the clearance of danger associated molecular patterns, such as amyloid-beta, via the glymphatic system. Since, $P$. gingivalis can transmigrate to the brain, and modulate organ-specific inflammatory innate and adaptive immune responses, this paper explores whether better management of indigenous periodontal bacteria could delay/prevent the onset and/or progression of dementia.
\end{abstract}

Key words: Alzheimer's disease, memory, manageable risk factor, periodontitis, $P$. gingivalis, sleep 


\section{Making a case for periodontitis as a risk factor for Alzheimer's disease}

Alzheimer's disease (AD) is the most common example of dementia, constituting $60-80 \%$ of all dementias, and the healthcare costs associated with the management of individuals with this condition keeps rising [1]. Unfortunately, the pathogenesis of the disease remains an enigma. There is no adequate treatment or prophylaxis for the disease at present. The solution rests on prevention, or finding an effective treatment for AD.

To this end, Baumgart and colleagues [2] reported on the mission of the newly formed World Dementia Council and outlined the key challenges of tackling dementia. One key priority is to examine the modifiable risk factors that influence the development of dementia [2]. A risk factor relationship between periodontal pathogens/periodontal disease and AD exists, as previously discussed by Olsen and Singhrao [3]. Salient points are that periodontal disease is co-morbid with clinically demented subjects [4-7]. Tooth loss in early and midlife has consequences for poor memory in later life [4, 7-12]. A prospective longitudinal study reported by Ide et al. [7] upholds the view that periodontitis is associated with a marked increase in cognitive decline, which is independent of base line cognition, in men with a mild to moderate clinical diagnosis of dementia. A study following the impact of a dental intervention on patients with a clinical diagnosis of mild AD found over 50\% of participants (who also suffered from gingivitis/periodontitis) showed improvements in their memory [6]. Oral bacteria and their virulence factors affect the central nervous system pathology [13, 14], and indiscriminate release of inflammatory mediators cause neuronal injury [5, 15-17]. The host's humoral responses to periodontal pathogen infections are ineffective, but if combined with other tests, they may prove useful as predictive biomarkers of $\mathrm{AD}$ [18-20]. The failure of Baumgart et al. [2] to recognise these facts prompted a response in the form of a letter to the Editor by Kamer et al. [21]. We also lend our support to recognize periodontitis as a risk factor in the context for $\mathrm{AD}$ pathogenesis [21] and provide further laboratory based research evidence from rodent brains infected with Porphyromonas gingivalis (P. gingivalis).

While the aging process is associated with an increased likelihood of periodontitis [22] and dementia, their onset is by no means inevitable. Just as some individuals fail to progress beyond gingivitis [23], others 
retain cognitive functioning throughout their life [24, 25]. Individuals who retain cognitive functioning in later life also show a low lifetime risk for cancer, diabetes, cardiovascular disease(s) [26, 27] and possibly periodontitis. Oral bacteria are associated with diverse pathologies, which are often co-morbid with AD (Fig. 1) as described elsewhere [28]. As periodontitis is an easily manageable risk factor for a number of conditions, we argue that reducing the incidence of periodontal disease is a preventative measure for numerous health benefits in later life.

\section{Periodontal disease}

Periodontitis describes a chronic polymicrobial infection in which $P$. gingivalis represents a keystone pathogen [29] and initiates dysbiosis [30] for nutritional dependency and imparting greater immune armamentarium to sustain the newly developing microbial communities in the sub-gingival niche. Until recently, it was acceptable to relate $P$. gingivalis interactions with specific species of bacteria, for example, those belonging to the red complex (Treponema denticola and Tannerella forsythia) [31]. However, to explain periodontal disease pathology, Hajishengalis and Lamont [30] have revised this view into a polymicrobial synergy and dysbiosis model. Hajishengalis and Lamont [30] propose that several hundreds of bacteria identified from the oral cavity (The oral microbiome http://www.homd.org) all have the potential to subvert immune defenses, and overcome protective host barriers by gaining greater virulence from the keystone pathogen in the susceptible host. This process is like a form of bacterial radicalization where seemingly inert species co-aggregate, whilst dwelling in the oral cavity. Co-aggregation of P. gingivalis with Streptococcus gordonii is a typical example of how synergy between local commensals and a keystone pathogen may be possible [32]. Taken together these newly armed, select communities of bacteria with greater virulence can impair the host’s immune surveillance, and tip the balance from homeostasis to dysbiosis [30].

Periodontitis consistently shows progressive destruction of gingival connective tissue and adjacent alveolar bone $[3,29]$. The initial gingival epithelial cell breach is the result of $P$. gingivalis being able to infect and survive within neutrophils that normally survey the gingival health [33]. The transient disablement of 
inflammatory signalling pathways attenuate neutrophil recruiting chemokine, interleukin 8 (IL-8), and cause imbalance of T cell IL-17 levels [34]. These changes promote local dysbiosis and therefore increase local inflammation, which is beneficial for selection and survival of the most resilient inflammophilc dysbiotic species within that oral niche $[33,35]$. The oral bacterial/virulence factor will then transmigrate to the AD brain, with neuroinflammation as an obvious outcome [14]. Already disturbed adaptive immune responses, as is apparent from the host suffering from periodontal disease [34], will give rise to oral pathology. Marsh et al. [36] have verified the role of adaptive immune cells in the immune-deficient transgenic AD mouse model (Rag5xfAD). This report confirms that adaptive immune cells in an immune-sufficient host (control animals) help to restrain both neuroinflammation and accumulation of $A \beta$ protein [36], suggesting organ specific hallmark pathology can develop in the immunosuppressed vulnerable host.

The suggested association between periodontal disease and AD relies on several key observations. First, there are significant correlations between the rate of cognitive decline and measures of periodontal disease progression, such as pocket depth, alveolar bone loss and tooth loss [37]. Currently, the relevance of newly identified risk factor, cognitive deficit for periodontitis [8], is more difficult to measure and pinpoint. We have suggested an explanation following our studies performed in the P. ginigivalis mono-infection model of periodontal disease in apolipoprotein E knockout (ApoE ${ }^{-/}$) mice (see section on blood-brain barrier below). Future research will undoubtedly highlight a better understanding of the pathophysiology of poor memory development in relation to the human form of periodontitis.

\section{Alzheimer's disease}

$\mathrm{AD}$ is a neurodegenerative disease characterised clinically by generalised loss of numerous markers of social values. Of major interest here are irreversible memory loss and sleep pattern disturbances [38-41]. Pathologically, the presence of significant numbers of two specific microscopic lesions (extracellular amyloidbeta (A $\beta)$ deposits, and intracellular hyperphosphorylated tau protein coated neurofibrillary tangles) is critical to AD diagnosis. Major risk factors for AD include aging, and genetic susceptibilities [42]. Co-morbid states 
include cerebrovascular strokes [43-45] with and without diabetes [46, 47]. The salient environmental factors, which can increase AD onset, include physical injury and peripheral infections [48] (Fig. 2).

A diverse list of candidate microbes that appear to be associated with, and survive the highly inflammophilic environment of the AD brain, is given by Olsen and Singhrao, [3]. However, there is a paucity of information as to whether there is synergy among multiple-species identified from AD brains, as is suggested, for example, in the oral biofilm bacteria [30]. Miklossy implicates oral and non-oral spirochaetal infections [13, 49] as dominant AD pathogens. However, microbes, such as Chlamydophila pneumoniae [50], Helicobacter pylori [51], Herpes simplex virus type 1 [52], and LPS from Gram-negative bacteria [14, 53], are documented as being identified in AD post-mortem brain specimens. This hypothesis implies the existence of an $\mathrm{AD}$ specific, but yet incomplete microbiome, consisting of a consortium of inflammophilic pathogens indigenous to oral and remote body organs. Intensive research is underway with newer hypotheses incorporating $\mathrm{A} \beta$ senile plaques as by-products of bacterial biofilm matrices [54, 55], and determining the existence of synergy among multiple-microbial species. If this is the case, oral bacterial infections will reveal their potential to cause/modulate the late-onset AD with possible synergy with other spirochetes as suggested elsewhere [49, 56].

\section{The blood-brain barrier}

Finding oral bacteria in post-mortem AD brains is intriguing. To this end, our research in the $P$. gingivlais infected $\mathrm{ApoE}^{-/-}$periodontal disease mouse model [57] continues to search for scientifically relevant clues. Our research findings in chronic P. gingivalis infection of $\mathrm{ApoE}^{-/-}$mice suggest the integrity of the hippocampal blood-brain barrier (BBB) gradually erodes via an inflammation mediated physical injury of the cerebral parenchyma [58]. For the first time, $P$. gingivalis infection in mice has been associated with the loss of BBB integrity [58]. This is interesting, as the same pathological feature of the BBB exists during human aging [59] and in AD subjects with the APOE4 genetic phenotype [60]. AD subjects with the APOE4 susceptibility gene demonstrate a high proinflammatory cytokine (tumor necrosis factor-alpha or TNF- $\alpha$, IL-6 and IL-1 $\beta$ ) 
expression [61]. Since microbial infections promote interleukin class of cytokines (IL-6 and IL-1 $\beta$ ) and TNF- $\alpha$ secretion via the inflammasome formation [62], it is plausible to suggest that individuals with APOE4 genotype are prone to harboring chronic infections and the cytokine burden is secondary to infections. For example, the genetically modified phenotype of $\mathrm{ApoE}^{-/-}$mice is predisposed to intrinsic stress in the form of higher burden of vascular inflammation, due to the constitutive expression of the pro-inflammatory cytokine TNF- $\alpha$ [63, 64]. Consequently, they are more sensitive to local and peripheral innate immune mediators (cytokines) released following daily bacteraemia from experimental periodontitis [57]. This correlates with daily bacteraemias that occur in humans due to periodontitis [65, 66]. A defective BBB [59, 60] would allow entry of pathogens and their immunogenic virulence factors and non-infection related molecules into the brain. Entry of bacteria and bacterial products will trigger oxidative stress followed by continually stimulating microglia to express inflammatory cytokines locally and generate neurodegeneration by mitigating protection of neurons from extrinsic insults.

There is little doubt that recurrent infections of the elderly increase the odds for developing AD [67]. The deteriorating BBB following $P$. gingivalis infection in mice [58] helps to explain the possible delirium post infections observed in elderly awaiting clinical AD diagnosis [67]. With regard specifically to periodontal disease, one longitudinal study has suggested a link between higher A $\beta$ load in the hippocampus of elderly humans with mild forms of periodontitis [37]. Singhrao et al. [58] are suggesting the role of P. gingivalis in inflammation mediated injury with progressive deterioration of the hippocampal microvascular integrity in the very regions of the brain that demonstrate a high burden of neuropathological hallmarks of AD. These observations are similar to the effect of physical insults, such as traumatic brain injury and stroke, which also lead to cognitive deficit (Fig. 2), aggregated hallmark protein accumulation and eventually AD [45, 68]. Both infections and physical brain trauma show common inflammatory mediators in their eventual manifestation of dementia [17, 69, 70].

Nutritional deficiency also correlates with cognitive decline [71], and fewer teeth may lead an individual reducing their intake of fresh foods, which in turn may decrease intake of B-vitamins and folic acid and other 
forms of nutrition [28]. Taken together, factors causing deterioration in cognition are multifactorial and complex with likely contribution from primary infection and nutritional deficiency due to loss of teeth. For example, depression can manifest from the generalized feeling of being unwell and can suppress appetite. Furthermore, $\mathrm{AD}$ is a depressive condition that can also lead to sufferers having reduced appetite.

Bacterial infections, specifically those that are involved in the onset of stroke, can also lead to AD in survivors [43-45]. Systemic hypoxia from co-morbid vascular states (atherosclerosis/stroke) [72, 73] and paucity of peripheral adaptive immune cells in the AD brain, and from Rag-5xfAD mice, demonstrates enhanced neuroinflammation and $\mathrm{A} \beta$ accumulation compared to control animals [36]. This research helps to explain $\mathrm{A} \beta$ deposition and abnormal tau phosphorylation post stroke. The chronic $P$. gingivalis infection of $\mathrm{ApoE}^{-/-}$mice show inflammation mediated physical damage that appears to be similar to that seen in traumatic brain injury or concussion cases with shared inflammatory biomarkers [58, 69]. These facts demonstrate how chronic infection of the brain with a keystone pathogen, such as P. gingivalis, can cause potentially serious consequences for the $\mathrm{BBB}$ and subsequent poor mental health. Future research should include AD transgenic mice with oral infections to support the preliminary findings of Singhrao et al. [58].

\section{Sleep}

Sleep is a physiological process, which reduces responsiveness and induces immobility on a temporary basis [74] in order to rest the body and support several brain functions including mood, memory, and consciousness [75]. Two main biological drivers govern sleep. The first is the homeostatic pressure to sleep, which rises as the amount of time increases since the last sleep period [76]. The second driver is the body’s endogenous circadian timing mechanism, which controls the timing and organization of sleep and is located in the hypothalamic suprachiasmatic nuclei (SCN) [40, 77]. During sleep, changes in the brain’s electrical activity observed via cortical electroencephalogram (EEG) patterns define two different behavioural states. The first observable state is non-rapid eye movement sleep characterized by the presence of "theta waves” and "delta waves”. Second is rapid eye movement sleep characterized by EEG patterns similar to people who are awake 
but distinguished by the presence of phasic events (twitching limbs), and tonic phenomena (loss of muscle tone) [78].

Research has pointed to a clear link between sleep duration and quality and physical health [79]. Short sleep durations (less than 6h) and poor sleep quality can increase the likelihood of mortality [80, 81] and specifically increase susceptibility to illnesses, such as coronary heart disease [82] and Type 2 diabetes [83]. Indeed, lack of sleep and poor sleep quality appear to impact negatively on the body's metabolic [84], endocrine and immune functioning [85]. Furthermore, recent research has suggested that although healthy younger cohorts can compensate for the impact of sleep-deprivation or poor sleep quality, older adults and those with AD appear to suffer more markedly from disrupted sleep-wake cycles [86]. In addition, the process of aging can affect negatively on the mechanisms controlling sleep. In the elderly, the aging of the SCN can lead to a decrease in neuronal activity, which in turn can cause changes in the circadian regulation and secretion of the sleep hormone melatonin [76]. Furthermore, an older population may have more psychological [87] and physiological [88] risk factors for poor sleep.

Specifically within the AD population, there are marked changes in sleep with increases in disturbed night sleep and increased daytime napping. It is therefore plausible to suggest that poor sleep (both duration and quality) could increase the risk of developing AD [89] in the elderly. However, once AD is established, deterioration in the circadian system that controls sleep-wake cycles [90] may be the direct or indirect result of disease processes that lead to increased sleep disturbances. Patients with AD who have been institutionalized (hospital setting), for example, show the marked disturbances in circadian patterns perhaps due to limited exercise and daylight exposure [91]. However, as AD progresses the damage to the neuronal pathways that initiate and maintain sleep become more pronounced and lead to increased problems with sleep [89, 92, 93]. For example, AD patients show increased theta activity during non-rapid eye movement sleep [94]. Such changes in sleep can destabilize both physiological processes, such as immune function, and impact on cognitive processes, such as memory (Fig. 3). As the impact of sleep appears to be bidirectional, it may be that stabilization of sleep patterns reduce the symptoms [95]. 
It is clear that sleep can affect the development [89] and progression [96] of AD. However, the precise way in which deregulated sleep may influence AD is not clear. An interesting link between sleep and the host's immune system is suggested [97], which links infections, inflammation and disturbed sleep-wake cycles. However, until the recent discovery of the glymphatic system, it was not clear what processes could be mediating the link between poor sleep and AD. The glymphatic system was discovered using two-photon imaging of live mice via a closed cranial window [98]. The glymphatic system uses the glial water channels to perform a clearance function within the brain similar to that of the peripheral lymphatic system [99, 100]. Therefore, the glymphatic system is important for the removal of danger associated molecular patterns such as microbial debris, interstitial solutes and $A \beta$ plaques from the brain [101]. Interestingly, the glymphatic system appears to be "turned on" during normal sleep and reduces in function during the awake state [101]. Therefore, if individuals are suffering from sleep abnormalities then the reduced functioning of the glymphatic system could increase levels of $\mathrm{A} \beta$ plaque formation and hyperphosphorylated tau neurofibrillary tangles. This may explain why poor sleep duration and quality can lead to the development of, and accelerate the progression of AD $[102,103]$. Therefore, the down regulation of the glymphatic system because of aging and mixed pathological factors and intrinsic stress due to infections, which affect sleep quality and duration, may interact to influence AD development and progression (Fig. 3).

Impairments to the glymphatic system may specifically reduce the brains ability to clear microbes such as $P$. gingivalis. Direct infiltration of the brain by microbes such as $P$. gingivalis can directly lead to neuroinflammation through activation of cortical microglia and contribute to local immune responses [104]. Paolicelli and colleagues [105] reported that microglia play a key role in scavenging and pruning normal neuronal network connections for brain development, and this activity is greater when the animal is asleep. Takayama et al. [106] noted that $P$. gingivalis infection of mice brains caused sleep pattern disturbances by altering glial cell light/dark molecular clock activity. $P$. gingivalis therefore, can subvert the host's microglial cell phagocytic activity by disrupting the circadian system that controls sleep-wake cycles. Consequently, the glymphatic system appears less efficient. This important and original finding by Takayama et al. [106] links the 
keystone periodontal pathogen, $P$. gingivalis, to sleep disturbances and subversion of microglial cell function, and paves the way for aggregated protein build-up. This report has crucial relevance to sleep pattern disturbances in $\mathrm{AD}$ and supports how poor oral hygiene and the associated rising levels of intrinsic and extrinsic sources of cytokines may act as crucial early modifiers of neurodegeneration and disease severity leading to deteriorating memory, sleep and ultimately the development of pathology.

\section{Ways to mitigate risk factors}

\section{Oral hygiene}

From an oral hygiene aspect, even having teeth (being dentate) but not maintaining daily oral hygiene appears to increase the risk (22-65\%) of dementia compared to those who brush their teeth daily [107]. A healthy oral cavity has normal microbiome, consisting largely of non-pathogenic commensal bacteria. These adhere to oral surfaces in the form of a biofilm. Any disruption of their environmental equilibrium can lead to polymicrobial synergistic dysbiosis resulting in periodontitis. For good gingival health and protection against periodontal disease, effective tooth brushing techniques (twice a day) for 2 minutes, using toothpaste with fluoride (containing a minimum of 1350 parts per million fluoride) is recommended. Combining brushing with interdental cleansing (e.g. interdental brushing once before bedtime) will aid physical removal of plaque from in between teeth and help to control host's inflammatory response to plaque. Individuals should be encouraged to visit the dentist regularly to improve their oral health no matter what their predisposition in health. For example, patients with clinical AD are less able to perform a recommended daily oral hygiene routine mainly due to ongoing cognitive impairment, and their dental check-ups are reliant on the freedom of their caregiver. As periodontitis is treatable, it offers the potential to reduce AD progression, if managed correctly (Fig. 1). Therefore, the dental intervention for $\mathrm{AD}$ patients should be high on the priority scale. Ultimately, the caregivers will need to take on-board the advice from dental professionals and change personal lifestyle and habits to minimise the severity of disease. 


\section{Diet}

Poor diet combined with a non-active life style leads to nutritional deficiencies and development of metabolic abnormalities. These include increases in the following: insulin resistance and chronic inflammation, oxidative stress-induced proteins, lipids, DNA damage and alterations in neuroendocrine systems [108-113]. Calorie reduction, resulting in a body mass index (BMI) of a healthy range of 19-23 is beneficial for bone density [114]. Moderate exercise leads to improved glucose tolerance and insulin action, and reduction in cardiovascular disease risk factors including plasma low-density lipoproteins-cholesterol concentration [115, 116]. Excessive exercise may increase the subjects' metabolic rate, which in turn can act as a disease-based risk factor. Individuals prone to recurrent microbial infections show increased TNF- $\alpha$ level despite consuming a healthy diet suggesting the oxidative stress from infections is of a higher magnitude than the host can manage. Alternatively, aging and $\mathrm{AD}$ processes also lead to a gradual accumulation of oxidative stress and molecular damage suggesting existence of incomplete efficiency in anti-oxidative and repair mechanisms in the host [117].

Certain foods have a beneficial impact on health. Plant foods contain a range of phytochemicals and vitamins, which are associated with reduced oxidative stress and inflammation. These natural anti-oxidants help to prevent cardiovascular disease and cancer [118, 119]. A diet high in foods containing phytochemicals such as onion, garlic, wild blueberries, tea, cabbage, carrot, celery and soya may reduce oxidative stress and inflammation [120], whilst some grain-based foods may destabilize blood glucose levels. In addition, oily fish high in omega-3 and omega-6 polyunsaturated fatty acids can positively affect the regulation of inflammation by increasing levels of eicosanoids [121]. Therefore, a healthy diet could reduce metabolic abnormalities, oxidative stress and inflammation, which in turn, can control the progression of periodontitis and subsequently slow down AD progression. 


\section{Conclusions}

Periodontitis constitutes a peripheral oral infection, the pathogenic components of which may result in infecting the brain and/or exposing the brain to immunogenic virulence factors and inflammatory mediators implicated in the pathogenesis of $\mathrm{AD}$. A prospective interventional study has shown that effectively treating periodontitis can lead to improvements in cognition. A chronic oral infection with P. gingivalis in $\mathrm{ApoE}^{-/-}$mice demonstrated peripheral and intracerebral inflammation is capable of compromising BBB integrity. A dysfunctional BBB can lead to many neurological diseases, including stroke, traumatic brain injury and AD. This demonstrates some relevance of a chronic infection of the brain with a keystone pathogen such as $P$. gingivalis, causing potentially serious consequences for the BBB and subsequent mental health. Others have shown that $P$. gingivalis infection can alter the microglial cell light/dark molecular clock activity, resulting in defective phagocytosis. This increases the prevalence of danger associated molecular patterns, which prevent normal functioning of neuronal networks as does a periodontal dysbiotic microbial community in subverting hosts innate and adaptive immune responses. Thus, risk factors for AD should also include periodontitis in addition to the more accepted factors, such as aging, genetic susceptibilities, stroke and traumatic brain injury.

Diet: The dietary regime should include foods that offer long-term protection from developing mixed pathologies (Fig. 1-3). The diet should include high intake of green leafy vegetables and blueberries, and oily fish because they appear to have anti-oxidant and anti-inflammatory properties as well as lowering cholesterol. Sleep: Good quality sleep appears to be critical for the glymphatic system to function. Glymphatic processes appear to have the potential to prevent and slow AD progression. Health practitioners should highlight the importance of good sleep alongside guidance on diet and physical activity. Other potential non-medical interventions include focusing on a diet high in foods that promote sleep and the use of light therapy. All of the above everyday activities (hygiene, dietary intake, and sleep) are changeable by the host's indigenous microbiome if their balance is disturbed. 


\section{Acknowledgements}

SKS wishes to thank the University of Central Lancashire for their continued financial support.

\section{Conflict of Interests}

There is no conflict of interests regarding the publication of this paper. 


\section{Legends}

\section{As in Harding et al., figure 1 on ppt}

Figure 1: Schematic to show knock-on effect from an oral condition such as periodontitis to the development of mixed pathologies in the order of periodontal disease, cardiovascular, and AD with input from metabolic disorders like type 2 diabetes. The arrows point to major risk factors with plausible effect on each condition. Mitigation of poor lifestyles are modifiable with dental intervention potentially slowing down/preventing these related conditions.

\section{As for Harding et al., figure 2 on ppt}

Figure 2: Schematic shows the relationship of various pathologies affecting memory. The single head arrows suggest a possible direction of disease progression with periodontitis as the initial condition. The double arrow heads point to known examples of diseases that negatively affect memory.

\section{As for Harding et al. figure 3 on ppt}

Figure 3: Schematic to show stress and the main risk factors influencing the circadian clock. All these factors, over time, lead to deterioration in memory. The arrows suggest a simplistic path for functional loss. 


\section{References}

[1] Prince M, Knapp M, Guerchet M, McCrane P, Prina M, Comas-Herrera A, Wittenberg R, Adelaja B, Hu B, King D, Rehill A, Salimkumar D (2014) Dementia UK: update. Second Edition, 1-62. https://www.youngdementiauk.org/sites/default/files/Dementia_UK_Second_edition_-_Overview.pdf

[2] Baumgart M, Snyder HM, Carrillo MC, Fazio S, Kim H, Johns H (2015) Summary of the evidence on modifiable risk factors for cognitive decline and dementia: A population-based perspective. Alzheimers Dement 11(6), 718-726.

[3] Olsen I, Singhrao SK (2015) Can oral infection be a risk factor for Alzheimer's disease? J Oral Microbiol 7, 29143. Review -http://dx.doi.org/10.3402/jom.v7.29143.

[4] Stein PS, Desrosiers M, Donegan SJ, Yepes JF, Kryscio RJ (2007) Tooth loss, dementia and neuropathy in the Nun study. J Am Dent Assoc 138, 1314-1322.

[5] Farhad SZ, Amini S, Khalilian A, Barekatain M, Mafi M, Barekatain M, Rafei E (2014) The effect of chronic periodontitis on serum levels of tumor necrosis factor-alpha in Alzheimer disease. Dent Res $J$ (Isfahan) 11(5), 549-552.

[6] Rolim Tde S, FabriGM, Nitrini R, Anghinah R, Teixeira MJ, Siqueira JT, Cesari JA, Siqueira SR (2014) Evaluation of patients with Alzheimer's disease before and after dental treatment. Arq Neuropsquiatr 72(12), 919-24.

[7] Ide M, Harris M, Stevens A, Sussams R, Hopkins V, Culliford D, Fuller J, Ibbett P, Raybould R, Thomas R, Puenter U, Teeling J, Perry VH, Holmes C (2016) Periodontitis and cognitive decline in Alzheimer's disease. PLoS One 11, e0151081.

[8] Stein PS, Kryscio RJ, Desrosiers M, Donegan SJ, Gibbs MB (2010) Tooth loss, apolipoprotein E, and decline in delayed word recall. $J$ Dent Res 89, 473-477.

[9] Kaye EK, Valencia A, Baba N, Spiro A $3^{\text {rd }}$, Dietrich T, Garcia RI (2010) Tooth loss and periodontal disease predict poor cognitive function in older men. J Am Geriatr Soc 58, 713-718.

[10] Okamoto N, Morikawa M, Tomioka K, Yanagi M, Amano N, Kurumatani N (2015) Association between tooth loss and the development of mild memory impairment in the elderly: the Fujiwara-kyo study. $J$ Alzheimers Dis 44(3), 777-786.

[11] Kondo K, Niino M, Shido K (1994) A case-control study of Alzheimer's disease in Japan - significance of life-styles. Dementia 5(6), 314-26.

[12] Gatz M, Mortimer JA, Fratiglioni L, Johansson B, Berg S, Reynolds CA, Pedersen NL (2006) Potentially modifiable risk factors for dementia in identical twins. Alzheimers Dement 2, 110-117.

[13] Riviere GR, Riviere KH, Smith KS (2002) Molecular and immunological evidence of oral Treponema in the human brain and their association with Alzheimer's disease. Oral Microbiol Immunol 17, 113-118. 
[14] Poole S, Singhrao SK, Kesavalu L, Curtis MA, Crean S (2013) Determining the presence of periodontopathic virulence factors in short-term post-mortem Alzheimer's disease brain tissue. $J$ Alzheimers Dis 36(4), 665-677.

[15] Watts A, Crimmins EM, Gatz M (2008) Inflammation as a potential mediator for the association between periodontal disease and Alzheimer’s disease. Neuropsychiatr Dis Treat 4, 865-876.

[16] Kamer AR, Craig RG, Dasanayake AP, Brys M, Glodzik-Sobanska L, de Leon MJ (2008) Inflammation and Alzheimer's disease: Possible role of periodontal diseases. Alzheimers Dement 4, 242-250.

[17] Kamer AR, Craig RG, Pirraglia E, Dasanayake AF, Norman RG, Boylan RJ, Nehorayoff A, Glodzik L, BrysM, de Leon MJ (2009) TNF $\alpha$ and antibodies to periodontal bacteria discriminate between Alzheimer’s disease patients and normal subjects. J Neuroimmunol 216, 92-97.

[18] Noble JM, Borrell LN, Papapnou PN, Elkind MSV, Scarmeas N, Wright CB (2009) Periodontitis is associated with cognitive impairment among older adults: Analysis of NHANES-III. $J$ Neurol Neurosurg Psychiatry 80, 1206-1211.

[19] Sparks Stein P, Steffen MJ, Smith C, Jicha G, Ebersole JL, Abner E, Dawson D 3rd. (2012) Serum antibodies to periodontal pathogens are a risk factor for Alzheimer's disease. Alzheimers Dement 8, 196203.

[20] Noble J, Scarmeas N, Papapanou P (2013) Poor oral health as a chronic, potentially modifiable dementia risk factor: review of the literature. Curr Neurol Neurosci Rep 13(10), 384. doi: 10.1007/s11910-0130384-X.

[21] Kamer AR, Janal MN, deLeon MJ (2015) Letter to the editor regarding: Summary of the evidence on modifiable risk factors for cognitive decline and dementia: A population-based perspective. Alzheimers Dement (Amst) 1(4), 385-386.

[22] Hajishengalis G (2014) Aging and its impact on innate immunity and inflammation: Implications for periodontitis. J Oral Biosci 56(1), 30-37.

[23] Trombelli L (2004) Susceptibility to gingivitis: a way to predict periodontal disease? Oral health Prev Dent 2 Supple 1, 265-269.

[24] Hitt R, Young-Xu Y, Silver M, Perls T (1999) Centenarians: The older you get the healthier you've been. Lancet 354, 652.

[25] Perls T (2004) Centenarians who avoid dementia. Trends Neurosci 27, 633-636.

[26] Lloyd-Jones DM, Leip EP, Larson MG, D’Agostino RB, Beiser A, Wilson PW, Wolf PA, Levy D (2006) Prediction of lifetime risk for cardiovascular disease by risk factor burden at 50 years of age. Circulation 113(6), 791-798.

[27] Imhof A, K“ovari E, von Gunten A, Gold G, Rivara CB, Herrmann FR, Hof PR, Bouras C, Giannakopoulos P (2007) Morphological substrates of cognitive decline in nonagenarians and centenarians: A new paradigm? J Neurol Sci 257, 72-79. 
[28] Shoemark DK, Allen SJ (2015) The microbiome and disease: reviewing the links between the oral microbiome, aging and Alzheimer's disease. J Alzheimer’s Dis 43, 725-738.

[29] Hajishengallis G, Darveau RP, Curtis MA (2012) “The keystone-pathogen hypothesis,” Nat Rev Microbiol 10(10), 717-725.

[30] Hajishengallis G, Lamont RJ (2012) Beyond the red complex and into more complexity: the polymicrobial synergy and dysbiosis (PSD) model of periodontal disease etiology. Mol Oral Microbiol 27(6), 409-419.

[31] Holt SC, Ebersole JL (2005) Porphyromonas gingivalis, Treponema denticola, and Tannerella forsythia: the "red complex", a prototype polybacterial pathogenic consortium in periodontitis. Periodontol 200038 , 72-122.

[32] Rickard AH, Gilbert P, High NJ, Kolenbrander PE, Handley PS (2003) Bacterial coaggregation: an integral process in the development of multi-species biofilms. Trends Microbiol 1(2), 94-100.

[33] Zenobia C, Hajishengalis G (2015) Porphyromonas gingivalis virulence factors involved in subversion of leukocytes and microbial dysbiosis. Virulence 6(3), 236-243.

[34] Darveau RP, Belton CM, Reife RA, Lamont RJ (1998) Local chemokine paralysis, a novel pathogenic mechanism for Porphyromonas gingivalis. Infect Immun 66, 1660-1665.

[35] Moutsopoulos NM, Konkel J, Sarmadi M, Eskan MA, Wild T, Dutzan N, Abusleme L, Zenobia C, Hosur KB, Abe T, Uzel G, Chen W, Chavakis T, Holland SM, Hajishengalis G (2014) Defective neutrophil recruitment in leukocyte adhesion deficiency type I disease causes local IL-17-driven inflammatory bone loss. Sci Transl Med 6(229), 229ra40. doi: 10.1126/scitranslmed.3007696.

[36] Marsh SE, Abud EM, Lakatos A, Karimzadeh A, Yeung ST, Davtyan H, Fote GM, Lau L, Weinger JG, Lane TE, Inlay MA, Poon WW, Blurton-Jones M (2016) The adaptive immune system restrains Alzheimer's disease pathogenesis by modulating microglial function. Proc Natl Acad Sci U S A 113(9), E1316-E1325.

[37] Kamer AR, Pirraglia E, TsuiW, Rusinek H,Vallabhajosula S, Mosconi L, Yi L, McHugh P, Craig RG, Svetcov S, Linker R, Shi C, Glodzik L, Williams S, Corby P, Saxena D, deLeon MJ (2015) Periodontal disease associates with higher brain amyloid load in normal elderly. Neurobiol Aging 36, 627-633.

[38] Satlin A, Volicer L, Stopa EG, Harper D (1995) Circadian locomotor activity and core-body temperature rhythms in Alzheimer’s disease. Neurobiol Aging 16(5), 765-771.

[39] Sinforiani E, Terzaghi M, Pasotti C, Zucchella C, Zambrelli E, Manni R (2007) Hallucinations and sleepwake cycle in Alzheimer's disease: a questionnaire-based study in 218 patients. Neurol Sci 28, 96-99.

[40] Musiek ES, Holtzman DM [2016] Mechanisms linking circadian clocks, sleep, and neurodegeneration. Science 354(6315), 1004-1008.

[41] Cedernaes J, Osorio RS, Varga AW, Kam K, Schioth HB, Benedict C (2017) Candidate mechanisms underlying the association between sleep-wake disruptions and Alzheimer's disease. Sleep Med Rev 31, 102-111. 
[42] Corder EH, Saunders AM, Strittmatter WJ, Schmechel DE, Gaskell PC, SmallGW, Roses AD, Haines JL, Pericak-Vance MA (1993) Gene dose of apolipoprotein E type 4 allele and the risk of Alzheimer's disease in late onset families. Science 261, 921-923.

[43] Pohjasvaara T, Erkinjuntti T, Ylikoski R, Hietanen M, Vataja R, Kaste M (1998) Clinical determinants of poststroke dementia. Stroke 29, 75-81.

[44] Desmond DW, Moroney JT, Paik MC, Sano M, Mohr JP, Aboumatar S, Tseng CL, Chan S, Williams JB, Remien RH, Hauser WA, Stern Y (2000) Frequency and clinical determinants of dementia after ischemic stroke. Neurology 54, 1124-1131.

[45] Henon H, Durieu I, Guerouaou D, Lebert F, Pasquier F, LeysD (2001) Poststroke dementia: Incidence and relationship to prestroke cognitive decline. Neurology 57, 1216-1222.

[46] Juhan-Vague I, Morange PE, Alessi MC (2002) The insulin resistance syndrome: implications for thrombosis and cardiovascular disease. Pathophysiol Haemost Thromb 32(5-6), 269-273.

[47] de la Monte SM (2009) Insulin resistance and Alzheimer’s disease. BMB Rep 42(8), 475-481.

[48] Maheshwari P, Eslick GD (2017) Bacterial infection increases the risk of Alzheimer's disease: An evidence-based assessment. J Alzheimer's Dis DOI 10.3233/JAD-160362.

[49] Miklossy J (2011) Alzheimer’s disease - a neurospirochetosis. Analysis of the evidence following Koch’s and Hill's criteria. J Neuroinflammation 8, 90.

[50] Balin BJ, Little CS, Hammond CJ, Appelt DM, Whittum-Hudson JA, G'erard HC, Hudson AP (2008) Chlamydophila pneumoniae and the etiology of late-onset Alzheimer's disease. J Alzheimers Dis 13, 371380.

[51] Honjo K, van Reekum R, Verhoeff NPLG (2009) Alzheimer's disease and infection: do infectious agents contribute to progression of Alzheimer's disease? Alzheimers Dement 5, 348-360.

[52] Itzhaki RF, Wozniak MA (2006) Herpes simplex virus type 1, apolipoprotein E, and cholesterol: A dangerous liaison in Alzheimer’s disease and other disorders. Prog Lipid Res 45, 73-90.

[53] Zhan X, Stamova B, Jin LW, DeCarli C, Phinney B, Sharp FR (2016) Gram-negative bacterial molecules associate with Alzheimer disease pathology. Neurology 87(22), 2324-2332.

[54] Allen HB, Morales D, Jones K, Joshi S (2016) Alzheimer’s Disease: A novel hypothesis integrating spirochetes, biofilm and the immune system. Neuroinfect Dis 7, 1.

[55] Miklossy J (2016) Bacterial amyloid and DNA are important constituents of senile plaques: Further evidence of Spirochetal and biofilm nature of senile plaques. J Alzheimers Dis 53(4), 1459-1473.

[56] Miklossy J (2015) Historic evidence to support a causal relationship between spirochetal infections and Alzheimer's disease. Front Aging Neurosci 7, 46. doi:10.3389/fnagi.2015.00046

[57] Velsko IM, Chukkapalli SS, Rivera MF, Lee J-Y, Chen H, Zheng D, Bhattacharyya I, Gangula PR, Lucas AR, Kesavalu L (2014) Active invasion of oral and aortic tissues by Porphyromonas gingivalis in mice causally links periodontitis and atherosclerosis. PLOS One 9, e97811. 
[58] Singhrao SK, Chukkapalli S, Poole S, Velsko I, Crean S, Kesavalu L (2017) Chronic Porphyromonas gingivalis infection accelerates the occurrence of age-related granules in $\mathrm{ApoE}^{-/-}$mice brains. J Oral Microbiol 9:1,1270602

[59] Montagne A, Pa J, Zlokovic BV (2015) Vascular plasticity and cognition during normal aging and dementia. JAMA Neurol 72, 495-496.

[60] Halliday MR, Rege SV, Ma Q, Zhao Z, Miller CA, Winkler EA, Zlokovic BV (2016) Accelerated pericyte degeneration and blood-brain barrier breakdown in apolipoprotein E4 carriers with Alzheimer's disease. $J$ Cereb Blood Flow Metab 36(1), 216-227.

[61] Candore G, Bulati M, Caruso C, Castiglia L, Colonna-Romano G, Di Bona D, Duro G, Lio D, Matranga D, Pellicano M, Rizzo C, Scapagnini, G, Vasto S (2010) Inflammation, cytokines, immune response, apolipoprotein E, cholesterol, and oxidative stress in Alzheimer disease: therapeutic implications. Rejuvenation Res 13, 301-313.

[62] Olsen I, Singhrao SK (2016) Inflammasome involvement in Alzheimer's disease. J Alzheimers Dis 54(1), 45-53.

[63] Roselaar SE, Daugherty A (1998) Apolipoprotein E-deficient mice have impaired innate immune responses to Listeria monocytogenes in vivo. J Lipid Res 39, 1740-1743.

[64] de Bont N, Netea MG, Demacker PN, Verschueren I, Kullberg BJ, van Dijk KW, van der Meer JW, Stalenhoef AF (1999) Apolipoprotein E knock-out mice are highly susceptible to endotoxemia and Klebsiella pneumoniae infection. J Lipid Res 40, 680-685.

[65] Forner L, Larsen T, Kilian M, Holmstrup P (2006) Incidence of bacteremia after chewing, tooth brushing, and scaling in individuals with periodontal inflammation. J Clin Periodontol 33 (6), 401-407.

[66] Lockhart PB, Bolger AF, Papapanou PN, Osinbowale O, Trevisan M, Levison ME, Taubert KA, Newburger JW, Gornik HL, Gewitz MH, Wilson WR, Smith SC Jr, Baddour LM (2012) Periodontal disease and atherosclerotic vascular disease: does the evidence support an independent association?: a scientific statement from the American Heart Association. Circulation 125, 2520-2544.

[67] Dunn N, Mullee M, Perry VH, Holmes C (2005) Association between dementia and infectious disease: Evidence from a case-control study. Alzheimer Dis Assoc Disord 19(2), 91-94.

[68] Abner EL, Nelson PT, Schmitt FA, Browning SR, Fardo DW, Wan L, Jicha GA, Cooper GE, Smith CD, Caban-Holt AM, Van Eldik LJ, Kryscio RJ (2014) Self-reported head injury and risk of late-life impairment and AD pathology in an AD center cohort. Dement Geriatr Cogn Disord 37, 294-306.

[69] Csuka E, Morganti-Kossmann MC, Lenzlinger PM, Joller H, Trentz O, Kossmann T (1999) IL-10 levels in cerebrospinal fluid and serum of patients with severe traumatic brain injury: relationship to IL-6, TNFalpha, TGF-beta1 and blood-brain barrier function. $J$ Neuroimmunol 101(2), 211-221.

[70] Holmes C, Cunningham C, Zotova E, Woolford J, Dean C, Kerr S, Culliford D, Perry VH (2009) Systemic inflammation and disease progression in Alzheimer's disease. Neurology 73, 768-774. 
[71] Mooijaart SP, Gussekloo J, Frolich M, Jolles J, Stott DJ, Westendorp RGJ, de Craen AJM (2005) Homocysteine, vitamin B-12, and folic acid and the risk of cognitive decline in old age: The Leiden 85plus study. Am J Clin Nutr 82, 866-871.

[72] Singhrao SK, Harding A, Simmons T, Robinson S, Kesavalu L, Crean StJ (2014) Oral inflammation, tooth loss, risk factors and association with progression of Alzheimer's disease. J Alzheimers Dis 1:42(3), 723737.

[73] Singhrao SK, Harding A, Chukkapalli S, Olsen I, Kesavalu L, Crean S (2016) Apoliporpotein E related comorbidities and Alzheimer's disease. J Alzheimers Dis 51(4), 935-948.

[74] Cirelli C, Tononi G (2008) Is sleep essential? PLoS Biol 6(8), e216.

[75] Kanda T, Tsujino N, Kuramoto E, Koyama Y, Susaki EA, Chikahisa S, Funato H (2016). Sleep as a biological problem: an overview of frontiers in sleep research. J Physiol Sci 66(1), 1-13.

[76] Luyster FS, Strollo PJ Jr, Zee PC, Walsh JK; Boards of Directors of the American Academey of sleep and the sleep research society (2012) Sleep: a health imperative. Sleep 35(6), 727-734.

[77] Rajaratnam SM, Howard ME, Grunstein RR (2013) Sleep loss and circadian disruption in shift work: health burden and management. Med J Aust 199(8), S11-15.

[78] Cirelli C, Tononi G (2015) Cortical development, electroencephalogram rhythms, and the sleep/wake cycle. Biol psychiatry 77(12), 1071-1078.

[79] Irwin MR (2015) Why sleep is important for health: a psychoneuroimmunology perspective. Annu Rev Psychol 66,143-172.

[80] Itani O, Jike M, Watanabe N, Kaneita Y (2016) Short sleep duration and health outcomes: a systematic review, meta-analysis and meta-regression. Sleep Med S1389-9457(16)30138-1. doi:10.1016/j.sleep.2016.08.006.

[81] Dew MA, Hoch CC, Buysee DJ, Monk TH, Begley AE, Houck PR, Hall M, Kupfer DJ, Reynolds CF $3^{\text {rd }}$ (2003) Healthy older adults' sleep predicts all-cause mortality at 4-19 years of follow-up. Psychosom Med 65(1), 63-73.

[82] Cappuccio FP, Cooper D, D’Elia L, Strazzullo P, Miller MA (2011) Sleep duration predicts cardiovascular outcomes: a systematic review and meta-analysis of prospective studies. Eur Heart J 32(12), 1484-1492.

[83] Cappuccio FP, D’Elia L, Strazzulllo P, Miller MA (2010) Quantity and quality of sleep and incidence of type 2 diabetes: a systematic review and meta-analysis. Diabetes care 33(2), 414-420.

[84] Spiegel K, Tasali E, Leproult R, Van Cauter E (2009) Effects of poor and short sleep on glucose metabolism and obesity risk. Nat Rev Endocrinol 5(5), 253-261.

[85] Miller MA, Cappuccio FP (2007) Inflammation, sleep, obesity and cardiovascular disease. Curr Vasc Pharmacol 5(2), 93-102.

[86] Lim AS, Kowgier M, Yu L, Buchman AS, Bennett DA (2013) Sleep fragmentation and the risk of incident Alzheimer's disease and cognitive decline in older persons. Sleep 36(7), 1027-1032. 
[87] Smagula SF, Stone KL, Fabio A, Cauley JA (2016). Risk factors for sleep disturbances in older adults: evidence from prospective studies. Sleep Med Rev 25, 21-30.

[88] Crowley K (2011) Sleep and sleep disorders in older adults. Neuropsychol Rev 21(1), 41-53.

[89] Benedict C, Byberg L, Cedernaes J, Hogankamp PS, Giedratis V, Kilander L, Lind L, Lannfelt L, Schioth HB (2015) SElt-reported sleep disturbance is associated with Alzheimer's disease risk in men. Alzheimers Dement 11(9), 1090-1097.

[90] Yesavage JA, Friedman L, Ancoil-Israel S, Bliwise D, Singer C, Vitiello MV, Monjan AA, Lebowitz B (2003) Development of diagnostic criteria for defining sleep disturbance in Alzheimer's disease. J Geriatr Psychiatry Neurol 16(3), 131-139.

[91] van Someren EJ, Hagebeuk EE, Lijzenga C, Scheltens P, de Rooij SE, Jonker C, Pot AM, Mirmiran M, Swaab DF (1996) Circadian rest—activity rhythm disturbances in Alzheimer's disease. Biol Psychiatry, 40(4), 259-270.

[92] Bliwise DL, Hughes M, McMahon PM, Kutner N (1995) Observed sleep/wakefulness and severity of dementia in an Alzheimer’s disease special care unit. J Gerontol A Biol Sci Med Sci 50(6), M303-306.

[93] Vitiello MV, Borson S (2001) Sleep disturbances in patients with Alzheimer's disease: epidemiology, pathophysiology and treatment. CNS Drugs 15(10), 777-796.

[94] Hot P, Rauchs G, Bertran F, Denise P, Desgranges B, Clochon P, Eustache F (2011) Changes in sleep theta rhythm are related to episodic memory impairment in early Alzheimer's disease. Biol Psychol 87(3), 334339.

[95] Wulff K, Gatti S, Wettstein JG, Foster RG (2010) Sleep and circadian rhythm disruption in psychiatric and neurodegenerative disease. Nat Rev Neurosci 11(8), 589-599.

[96] Mander BA, Winer JR, Jagust WJ, Walker MP (2016) Sleep: a novel mechanistic pathway, biomarker, and treatment target in the pathology of Alzheimer's disease? Trends Neurosci 39(8), 552-566.

[97] Opp MR, Krueger JM (2015) Sleep and immunity: A growing field with clinical impact. Brain Behav Immun, 47, 1-3.

[98] Jessen NA, Munk AS, Lundgaard I, Nedergaard M (2015) The glymphatic system: A beginner’s guide. Neurochem Res 40(12), 2583-2599.

[99] Nedergaard M (2013) Neuroscience. Garbage truck of the brain. Science 340(6140), 1529-30.

[100] IIiff JJ, Chen MJ, Plog BA, Zeppenfeld DM, Soltero M, Yang L, Singh I, Deane R, Nedergaard M (2014) Impairment of glymphatic pathway function promotes tau pathology after traumatic brain injury. $J$ neurosci 34(49), 16180-16193.

[101] Xie L, Kang H, Xu Q, Chen MJ, Liao Y, Thiyagarajan M, O’Donnell J, Christensen DJ, Nicholson C, lliff JJ, Takano T, Deane R, Nedergaard M (2013) Sleep drives metabolite clearance from the adult brain. Science 342(6156), 373-377. 
[102] Slats D, Claassen JA, Verbeek MM, Overeem S (2013) Reciprocal interactions between sleep, circadian rhythms and Alzheimer's disease: focus on the role of hypocretin and melatonin. Ageing Res Rev 12(1), 188-200.

[103] Ju-YE, McLeland JS, Toadebusch CD, Xiong C, Fagan AM, Duntley SP, Morris JC, Holtzman DM (2013) Sleep quality and preclinical Alzheimer’s disease. JAMA Neurol 70(5), 587-93.

[104] Poole S, Singhrao SK, Chukkapalli S, Rivera M, Velsko I, Kesavalu L, Crean StJ (2015) Active invasion of an oral bacterium and infection-induced complement activation in ApoE ${ }^{\text {null }}$ mice brains. J Alzheimers Dis 43, 67-80.

[105] Paolicelli RC, Bolasco G, Pagani F, Maggi L, Scianni M, Panzanelli P, Giustetto M, Ferreira TA, Guiducci E, Dumas L, Ragozzino D, Gross CT (2011) Synaptic pruning by microglia is necessary for normal brain development. Science 333(6048), 1456-1458.

[106] Takayama F, Hayashi Y, Wu Z, Liu Y, Nakanishi H (2016) Diurnal dynamic behaviour of microglia in response to infected bacteria through the UDP-P2Y6 receptor system. Sci Rep 6, 30006. doi: 10.1038/srep30006.

[107] Paganini-Hill A, White SC, Atchison KA (2012) Dentition, dental health habits, and dementia: the Leisure World Cohort Study. J Am Geriatr Soc 60(8), 1556-1563.

[108] Xu HY, Barnes GT, Yang Q, Tan Q, Yang DS, Chou CJ, Sole J, Nichols A, Ross JS, Tartaglia LA, Chen $\mathrm{H}$ (2003) Chronic inflammation in fat plays a crucial role in the development of obesity-related insulin resistance. J Clin Invest 112, 1821-1830.

[109] Rajala, MW, Scherer, PE. (2003) Minireview: The adipocyte - at the crossroads of energy homeostasis, inflammation, and atherosclerosis. Endocrinology 144, 3765-3773.

[110] Seals DR, Bell C (2004) Chronic sympathetic activation - consequences and cause of age-associated obesity? Diabetes 53, 276-284.

[111] Soldatos G, Cooper ME, Jandeleit-Dahm KA (2005) Advanced-glycation end products in insulin-resistant states. Curr Hypertens Rep 7(2), 96-102.

[112] Furukawa, S, Fujita, T, Shimabukuro, M, Iwaki, M, Yamada, Y, Nakajima, Y, Nakayama, O, Makishima, M, Matsuda, M, Shimomura, I. (2004) Increased oxidative stress in obesity and its impact on metabolic syndrome. J Clin Invest 114, 1752-1761.

[113] Smith SR, Lovejoy JC, Greenway F, Ryan D, deLonge L, de la Bretonne J, Volafova J, Bray GA (2001) Contributions of total body fat, abdominal subcutaneous adipose tissue compartments, and visceral adipose tissue to the metabolic complications of obesity. Metabolism 50(4), 425-435.

[114] Soltani S, Hunter GR, Kazemi A, Shab-Bidar S (2016) The effects of weight loss approaches on bone mineral desnity in adults: a systematic review and meta-analysis of randomized controlled trials. Osteoporos Int 27(9), 2655-2671.

[115] Ross, R, Dagnone, D, Jones PJ. (2000) Reduction in obesity and related comorbid conditions after dietinduced weight loss or exercise-induced weight loss in men. A randomized, controlled trial. Ann Intern Med 133(2), 92-103. 
[116] Weiss EP, Racette SB, Villareal DT, Fontana L, Steger-May K, Schechtman KB, Klein S, Holloszy JO (2006) Improvements in glucose tolerance and insulin action induced by increasing energy expenditure or decreasing energy intake: a randomized controlled trial. Am J Clin Nutr 84(5), 1033-1042.

[117] Mota SI, Costa RO, Ferreira IL, Santana I, Caldeira GL, Padovano C, Fonseca AC, Baldeiras I, Cunha C, Letra L, Oliveira CR, Pereira CM, Rego AC (2015) Oxidative stress involving changes in Nrf2 and ER stress in early stages of Alzheimer's disease. Biochim Biophys Acta 1852, 1428-1441.

[118] Kris-Etherton, PM, Hecker, KD, Bonanome, A, Coval, SM, Binkoski, AE, Hilpert, KF, Griel, AE, Etherton, TD (2002) Bioactive compounds in foods: their role in prevention of cardiovascular disease and cancer. Am J Med 113, 71S-88S.

[119] Liu, RH (2003) Health benefits from fruit and vegetables and from additive and synergistic combinations of phytochemicals. Am J Clin Nutr 78(3), 517S-520S.

[120] Fontana L (2009) Modulating human aging and age-associated diseases. Biochim Biophys Acta 1790(10), 1133-1138.

[121] Wall R, Ross RP, Fitzgerald GF, Stanton C (2010) Fatty acids from fish: the anti-inflammatory potential of long-chain omega-3 fatty acids. Nutr Rev 68(5), 280-289. 